\title{
Updating the evidence for the role of corticosteroids in severe sepsis and septic shock: a Bayesian meta-analytic perspective
}

\author{
John L Moran ${ }^{1 *}$, Petra L Graham², Sue Rockliff ${ }^{3}$, Andrew D Bersten ${ }^{4}$
}

\begin{abstract}
Introduction: Current low (stress) dose corticosteroid regimens may have therapeutic advantage in severe sepsis and septic shock despite conflicting results from two landmark randomised controlled trials (RCT). We systematically reviewed the efficacy of corticosteroid therapy in severe sepsis and septic shock.

Methods: RCTs were identified (1950-September 2008) by multiple data-base electronic search (MEDLINE via OVID, OVID PreMedline, OVID Embase, Cochrane Central Register of Controlled trials, Cochrane database of systematic reviews, Health Technology Assessment Database and Database of Abstracts of Reviews of Effects) and hand search of references, reviews and scientific society proceedings. Three investigators independently assessed trial inclusion and data extraction into standardised forms; differences resolved by consensus.

Results: Corticosteroid efficacy, compared with control, for hospital-mortality, proportion of patients experiencing shock-resolution, and infective and non-infective complications was assessed using Bayesian random-effects models; expressed as odds ratio (OR, (95\% credible-interval)). Bayesian outcome probabilities were calculated as the probability $(P)$ that $O R \geq 1$. Fourteen $R C T s$ were identified. High-dose (>1000 mg hydrocortisone (equivalent) per day) corticosteroid trials were associated with a null $(n=5$; OR 0.91(0.31-1.25)) or higher $(n=4$, OR 1.46(0.73-2.16), outlier excluded) mortality probability $(P=42.0 \%$ and $89.3 \%$, respectively). Low-dose trials $(<1000 \mathrm{mg}$ hydrocortisone per day) were associated with a lower $(n=9$, OR 0.80(0.40-1.39); $n=8$ OR 0.71(0.37-1.10), outlier excluded) mortality probability ( $20.4 \%$ and $5.8 \%$, respectively). OR for shock-resolution was increased in the low dose trials $(n=7$; OR 1.20(1.07-4.55); $P=98.2 \%)$. Patient responsiveness to corticotrophin stimulation was nondeterminant. A high probability of risk-related treatment efficacy (decrease in log-odds mortality with increased control arm risk) was identified by metaregression in the low dose trials $(n=9$, slope coefficient $-0.49(-1.14,0.27)$; $P=92.2 \%)$. Odds of complications were not increased with corticosteroids.

Conclusions: Although a null effect for mortality treatment efficacy of low dose corticosteroid therapy in severe sepsis and septic shock was not excluded, there remained a high probability of treatment efficacy, more so with outlier exclusion. Similarly, although a null effect was not excluded, advantageous effects of low dose steroids had a high probability of dependence upon patient underlying risk. Low dose steroid efficacy was not demonstrated in corticotrophin non-responders. Further large-scale trials appear mandated.
\end{abstract}

\section{Introduction}

In 1974, Weitzman and Berger reviewed the clinical trial design of studies reporting corticosteroid use in bacterial infections over the previous 20 years because of the controversial role of the therapeutic use of corticosteroids

\footnotetext{
* Correspondence: john.moran@adelaide.edu.au

'Department of Intensive Care Medicine, The Queen Elizabeth Hospital, 28 Woodville Road, Woodville, South Australia 5011, Australia
}

in acute infections [1]. It is ironic that 34 years later a similar sentiment was echoed: "For more than five decades, no other adjunctive therapy has been more consistently debated than the use of corticosteroids for severe sepsis and septic shock" [2]. A contemporaneous review concluded that the role of glucocorticoid therapy in intensive care remained uncertain [3]. In 1995, two meta-analyses found no benefit for high-(pharmacological)-dose corticosteroids in sepsis and septic shock $[4,5]$
C Biomed Central

(c) 2010 Moran et al.; licensee BioMed Central Ltd. This is an open access article distributed under the terms of the Creative Commons Attribution License (http://creativecommons.org/licenses/by/2.0), which permits unrestricted use, distribution, and reproduction in any medium, provided the original work is properly cited. 
and in 2004 another two meta-analyses [6,7] found benefit for long courses of low-(stress) [7]-dose corticosteroids. This benefit was either qualified: pending the results of the Corticosteroid Therapy of Septic Shock (CORTICUS) [8] study, clinical equipoise remained for the issues of adreno-corticotrophin (ACTH) administration, cortisol testing, and the therapeutic use of hydrocortisone [9]; or more definitive: '...a beneficial therapy to critically ill patients in septic shock' [10]. That the confirmatory [11] phase III CORTICUS study [8] was 'somewhat disappointing' [12] undoubtedly reflects this history of therapeutic uncertainty. Current guidelines advocate a role for intravenous hydrocortisone in adult septic shock patients who are poorly responsive to fluid and vasopressor therapy and, in the apparent absence of a mortality effect dependent on ACTH responsiveness, attention has been directed to the more rapid time-resolution of shock with corticosteroids $[13,14]$.

Thus the question still remains: what is the evidence, post CORTICUS [8], for the efficacy of corticosteroids in severe sepsis and septic shock? We undertook a systematic review and quantitative analysis of randomized controlled trials (RCT) addressing corticosteroid efficacy in severe sepsis and septic shock, updating [15] previous studies [6,7]. As the question of further large-scale trials to assess corticosteroids in septic shock has currently been canvassed [16], in particular the efficacy at high mortality risk [12], we addressed the risk-related efficacy of steroids within the trials considered [17] and estimated the predictive distribution for the underlying effect in new studies [18].

\section{Materials and methods Trial selection}

Randomised controlled trials in critically ill patients evaluating corticosteroid therapy versus no corticosteroid therapy in severe sepsis or septic shock were considered for inclusion. Only trials reporting mortality were included. We excluded: studies reporting only physiological endpoints (for example, changes in immunological variables); descriptive studies; retrospective cohort studies; studies in the pediatric population; and studies exclusively reporting series of meningitis, typhoid fever and pneumonia where sub-set analyses of patients of interest (for this meta-analysis) were not reported. Where there was missing data or ambiguity of data presentation, attempts were made to contact the study author(s) to resolve these issues.

\section{Search strategy and quality assessment}

An extensive computerized literature search was performed (SR) for the period of 1950 to September 2008 using the National Library of Medicine MEDLINE via OVID, OVID PreMedline, EBSCO Cinahl, OVID
Embase, Cochrane Central Register of Controlled trials, Cochrane database of systematic reviews, American College of Physicians Journal Club, Health Technology Assessment Database and Database of Abstracts of Reviews of Effects. We restricted the search to studies on adult human populations and used the Mesh, Embase and Cinahl thesaurus in addition to free text searching. The following terms were identified as the most relevant: sepsis or bacteremia or fungemia or pneumonia or septicemia or septic shock narrowed down with the terms hydrocortisone or corticosteroids or adrenal cortex hormones or steroids. The set was then further limited to randomised controlled trials or clinical trials or multicenter study and trials published in English. A detailed search strategy is provided in Additional file 1.

We reviewed the abstracts of trials generated by the electronic search and the full text of trials pertaining to corticosteroids in sepsis and septic shock were retrieved for a more detailed evaluation. Review articles were examined to identify additional trials. In addition a hand search of the proceedings of scientific meetings of the following journals was performed: American Journal of Respiratory and Critical Care Medicine, Chest, Critical Care Medicine, European Respiratory Journal, Intensive Care Medicine and Thorax.

\section{Quality assessment}

Three investigators (JLM, PLG, and AB) reviewed studies fulfilling inclusion criteria and pre-defined variables and outcomes were abstracted into standardized data abstraction forms. Quality assessment on the published studies was performed in an un-blinded fashion by two investigators (JLM, PLG) using the 11-point quality score of Cronin and colleagues [4]. Where there were differences in scoring, a consensus was reached. Extracted data was separately entered, reviewed and verified by two investigators (JLM, PLG) prior to analysis.

\section{Outcome measures}

The primary outcome was mortality assessment at hospital discharge. Secondary outcomes were resolution of shock (or withdrawal of inotropes) at 7 to 28 days and corticotrophin responsiveness, secondary infections and non-infective (gastro-intestinal bleeding and new-onset hyperglycemia) complications.

\section{Definitions}

Severe sepsis and septic shock were defined after the 1992 American College of Chest Physicians and Society of Critical Care Medicine Consensus Conference [19]. Pre-1992 studies were reviewed to establish consistency with this definition. Secondary infections were defined generally as a positive culture from a normally sterile 
site. The time span of the studies suggested that definitions for secondary infections would be subject to revision; for example, the use of quantitative cultures in more recent calendar years [20]. Shock resolution was defined as a stable hemodynamic state for a period of 24 hours or more after weaning of vasopressor support. Corticosteroid dose was converted into hydrocortisone equivalents (mg) and expressed as total maximum realizable dose [20] accounting for total time of exposure (therapeutic dose-time and tapering). Where patient corticosteroid dose-time schedule was unavailable due to death and/or reporting, we used median survival time from the published Kaplan-Meier curve.

\section{Statistical analysis}

The effect of corticosteroids compared with control on mortality; the proportion of patients experiencing shock-resolution at defined times; and infective and non-infective complications were assessed using Bayesian random-effects models [21], via WinBUGS software [22] using three simultaneous runs of the program with disparate starting values. The first 10,000 iterations were discarded and results were reported as the posterior median odds ratio (OR) with $95 \%$ credible intervals (CrI) on the basis of a further 100,000 iterations. As argued previously [20], the hazard ratio would have been the preferred metric for mortality effect due to varying event times. However, due to the variability in intra-trial reporting, this was not feasible. As the hazard ratio may be approximated from the OR [23], we chose the OR as an appropriate metric [24]. Bayesian parameter estimates, as opposed to frequentist, are probability distributions and hence there is no contradiction in computing both (i) a (median) point estimate and CrI and (ii) the posterior probability $(P)$ that, say, the OR is more than $1[25,26]$. That is, "Bayesian methodology also allows us to make statements about the probability that the ORs are greater than 1 in cases in which the associated 95\% CrI includes 1" [27]. A probability of $50 \%$ suggests a null effect, while $P$ of at least $90 \%$ signifies harm and $P$ less than $10 \%$ indicates benefit for the mortality, infective and non-infective endpoints and vice versa for the shock reversal endpoint [28]. Analysis was undertaken by stratifying between 'high-dose' and 'lowdose' corticosteroid therapy, as in Annane and colleagues [6] and after the categorization of daily treatment doses of hydrocortisone by Marik (high-dose corticosteroid $>1,000 \mathrm{mg}$ per day) [29].

Bayesian meta-regression [21] was used to determine the relation between log odds mortality and (i) average patient age and (ii) control-arm risk, as log-odds mortality $[17,24]$. The slope $(\beta)$ with $95 \% \mathrm{CrI}$ and the probability that $\beta \geq 0\left(P_{\beta}\right)$ were presented. Heterogeneity was presented as the standard deviation, $\tau$, between studies
[30]; $\tau$ close to 0 indicates little heterogeneity, $\tau=0.5$ indicates moderate and $\tau>1$ reflects substantial heterogeneity [18].

For heuristic purposes we separately estimated: (i) pooled estimates with the Schumer [31] and Cooperative Study Group (CSG) [32] studies removed in a sensitivity analysis due to previous identification of the former as a potential outlier [7] and the remoteness of the latter 1963 trial from current therapeutic regimens; (ii) certain parameters of clinical import in the risk difference metric [21], albeit this metric may suffer from potential bias with varying time to event [24]; (iii) the mortality OR and probability $(P)$ that the OR was 1 or more in the predictive distribution (that is, in the next 'new' study); (iv) the mortality OR for hypothesized studies of size 2,000 and 4,000 patients; (v) the Bayesian predictive $P$-value that the CORTICUS trial [8] was inconsistent with the other trials of the low-dose corticosteroid group; that is, the CORTICUS study was omitted from analysis (leaving $n=7$ trials) and a replicate study of the same size as the CORTICUS study was drawn, with a replicate baseline, and a new treatment effect was established based upon the predictive distribution. A Bayesian predictive P-value was subsequently obtained, expressing the probability that the future study would be as 'extreme' as that observed.

Publication and the associated phenomenon of smallstudy bias were addressed using the approach of Peters and colleagues [33] via contour-enhanced funnel plots; formal quantitative testing for small-study-bias was performed using the approach of Harbord and colleagues [34], which has effective properties in the presence of appreciable heterogeneity. Implementation was via the $R$ package 'meta' [35] and user-written routines.

\section{Results}

Using multiple electronic searches, 1,843 abstracts of published papers were identified (including duplicates). A review of these abstracts (JLM, PLG) identified 115 papers of potential interest including review papers. The published text of 31 'randomized' clinical trials, including seven abstracts from proceedings of scientific meetings, were further reviewed (JLM, PLG, AB): two were excluded on the basis of reporting from previous trials, one reported no mortality outcome data and one used pseudo-randomization. A further 13 studies, including four abstracts-only were excluded for reasons given in Table 1. The final cohort was of 14 trials $[8,31,32,36-46]$, including two abstracts from the reports of scientific meetings; 11 of the studies had been considered by previous meta-analyses $[4-6,10]$ and the three remaining studies $[8,42,44]$ were post-2004, the publication date of the two comparator meta-analyses $[6,7]$ (Figure 1 and Table 2). The trial patient size varied 
Table 1 Study exclusions

\begin{tabular}{|c|c|c|}
\hline Study & $\begin{array}{l}\text { Year } \\
\text { published }\end{array}$ & Reason for exclusion \\
\hline $\begin{array}{l}\text { Wagner and colleagues } \\
\text { [78] }\end{array}$ & 1955 & Description of pneumonia therapy only with no severity stratification. Allocation by 'history number' \\
\hline $\begin{array}{l}\text { Thompson and } \\
\text { colleagues [79] }\end{array}$ & 1976 & $\begin{array}{l}\text { Abstract; nine of } 60 \text { patients with cardiogenic shock; no subset analyses. Post-randomization exclusion of } \\
4 \text { patients }\end{array}$ \\
\hline $\begin{array}{l}\text { Lucas and Ledgerwood } \\
\text { [80] }\end{array}$ & 1984 & Open-label study; pseudo-randomization by hospital number \\
\hline VASSCS [81] & 1987 & $\begin{array}{l}\text { Predominantly sepsis patients with no subgroup of shocked patients. No timing of fluid bolus with } \\
\text { respect to reported hypotension }\end{array}$ \\
\hline $\begin{array}{l}\text { Schattner and colleagues } \\
\text { [82] }\end{array}$ & 1997 & pseudo-randomization of patients with 'early sepsis' \\
\hline Keh and colleagues [60] & 2003 & Cross-over placebo study in septic shock \\
\hline $\begin{array}{l}\text { Confalonieri and } \\
\text { colleagues [83] }\end{array}$ & 2005 & Community acquired pneumonia study; no subset analyses for shocked patients \\
\hline $\begin{array}{l}\text { Rinaldi and colleagues } \\
\text { [84] }\end{array}$ & 2006 & Post randomization exclusion of 15 patients; 3 with septic shock \\
\hline Huh and colleagues [85] & 2006 & Abstract; two hydrocortisone arms; no concurrent placebo arm reported \\
\hline Loisa and colleagues [86] & 2007 & Two hydrocortisone arms; no concurrent placebo group \\
\hline $\begin{array}{l}\text { Nawab and colleagues } \\
{[87]}\end{array}$ & 2007 & Abstract; severe community acquired pneumonia, no subset analysis; outcomes today-7 only \\
\hline $\begin{array}{l}\text { Cicarelli and colleagues } \\
\text { [88] }\end{array}$ & 2007 & Unspecified post-randomization exclusion of 'all patients who progressed to refractory septic shock' \\
\hline $\begin{array}{l}\text { Kurugundla and } \\
\text { colleagues [89] }\end{array}$ & 2008 & Abstract; ICU outcomes reported only \\
\hline
\end{tabular}

VASSCS, Veterans Administration Systemic Sepsis Cooperative Study.

from 28 [44] to 499 [8] and the total number of patients was 1,991 , of mean age 55 years and $66 \%$ male. Total corticosteroid dosage in the high-dose cohort ranged from 7,000 to 42,000 hydrocortisone-equivalent mg over one to three days, whereas in the low-dose cohort, dosage was 856 to 2,175 hydrocortisone-equivalent $\mathrm{mg}$ over 2 to 10 days treatment with 0 to 14 days of tapering (Table 3). Average high- and low-dose control arm mortalities were $47 \%$ and $54 \%$, respectively. Further characteristics of the trials are given in Tables 2 and 3.

The primary outcome of hospital mortality was available in six studies $[8,32,36,39,43,46]$; the other studies had recorded 28- or 30-day mortality and one study recorded 14-day mortality (Table 2 ). Sepsis and shock definitions of trials completed before 1992 $[31,32,38,41,43,46]$ were generally consistent with definitions of the American College of Chest Physicians and Society of Critical Care Medicine Consensus Conference on sepsis and organ failure, albeit the two trials published in 1971 [41] and 1963 [32] used 'life threatening infections' as a criteria (Table 2). Of interest, trials before 1998 were predominantly reported from the USA; after 1997, they were from European and other non-USA sites. Trial patient data by outcomes (hospital mortality; shock-reversal; corticotrophin-responsiveness; shock reversal by corticotrophin-responsiveness; and secondary complications, as infectious, gastro-intestinal bleeding and new-onset hyperglycemia) are shown in Table 4.

\section{Mortality outcome}

Neither the low-dose nor high-dose cohort showed a significant steroid treatment effect for the mortality OR, although there was modest evidence of benefit in the low-dose cohort $(P=20.4 \%)$ (Table 5 and Figure 2$)$. The odds of mortality (four studies $[8,36,42,45]$ ), for both corticotrophin responders and non-responders was not significantly different compared with control (Table 5).

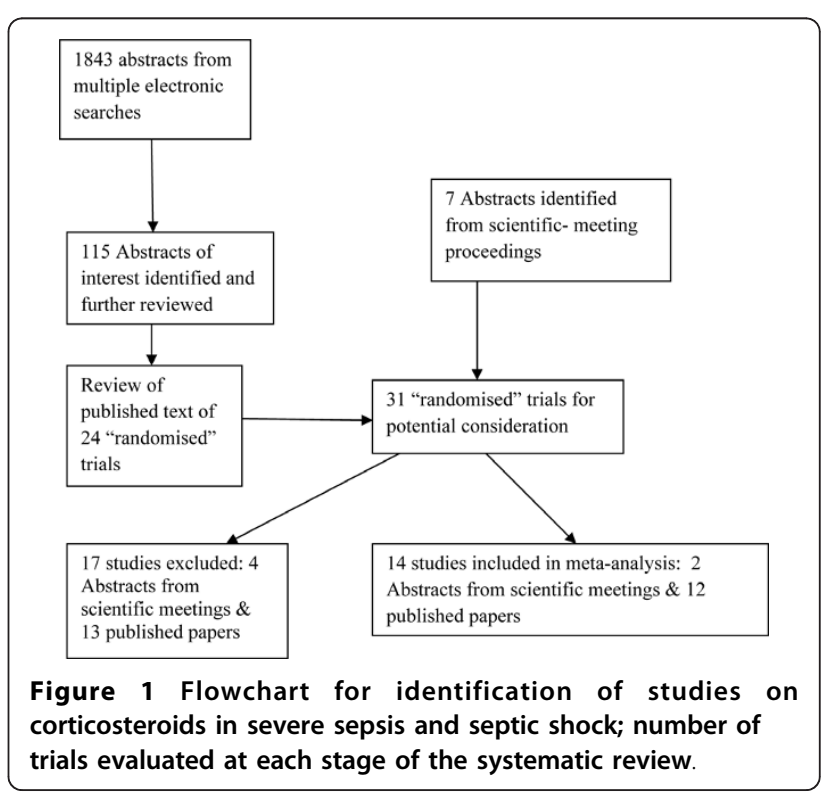




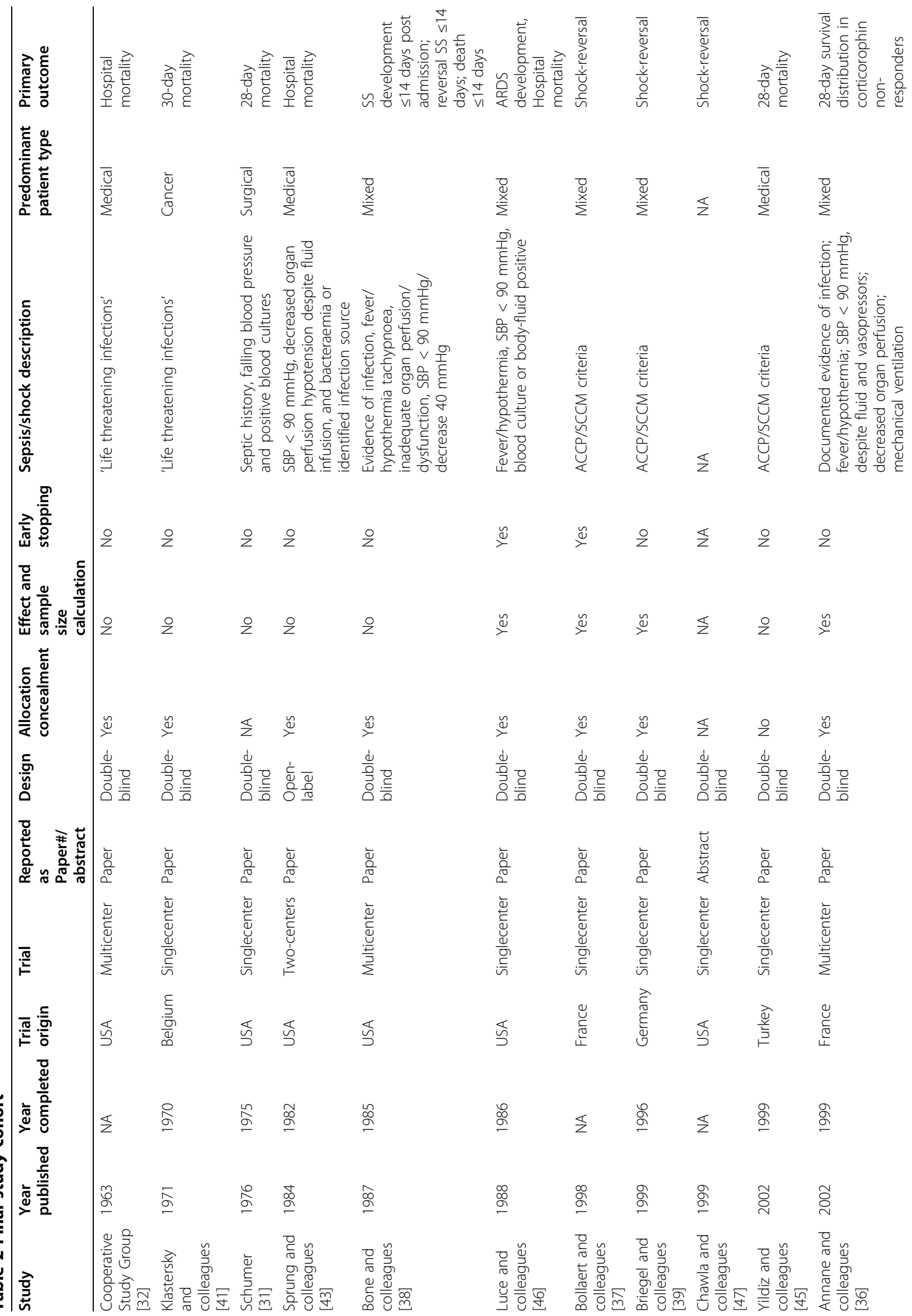




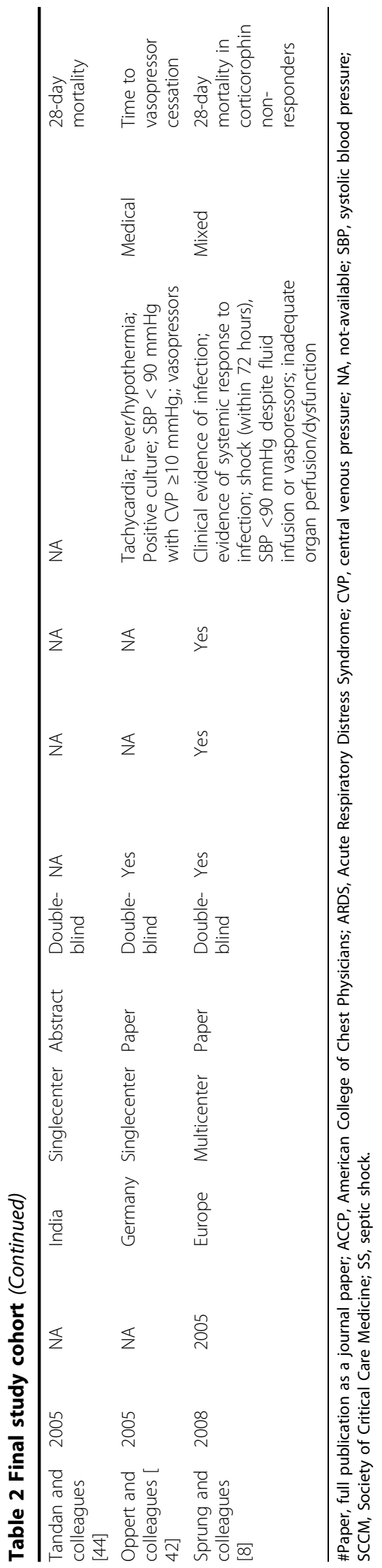

A contour-enhanced funnel plot showed no obvious asymmetry in terms of a lack of small studies with a null or adverse steroid effect (Figure 3), this was not rejected (at the 0.1 level) using the quantitative approach of Harbord and colleagues [34] $(P=0.146)$. The low-dose studies showed a degree of asymmetry of the contour-enhanced funnel plot (Figure 4), but the quantitative estimate did not confirm this $(P=0.113)$.

\section{Shock reversal}

Median vasopressor time (six studies $[8,36,37,39,42,47]$ ) ranged from 2 to 7 days for steroid-treated patients and 5 to 13 days for placebo. With respect to the number of patients experiencing shock reversal, there was no clear steroid treatment-effect (overall OR included 1) for high-dose studies $(n=2)$. However, there was a high probability of benefit for the low-dose cohort; moderate heterogeneity being present (Figure 5 and Table 5). Odds of shock-reversal were not substantially different for corticotrophin non-responders or responders; however, both had a high probability of benefit (Table 5).

\section{Metaregression}

Univariate metaregression of average age against log odds mortality yielded no significant effects although $P_{\beta}$ was high and the slope positive for both low- and highdose cohorts. This indicated some evidence that, on average, older study participants had increased odds of mortality under steroid treatment versus control (Table 5). Similarly, although the metaregression of underlying control-arm risk against log odds mortality yielded no significant effects, for the low-dose cohort, $P_{\beta}$ was small and the slope negative, indicating a high probability that as the underlying risk of mortality increased the log odds mortality under steroid treatment decreased (Table 5). The removal of the CSG study [32] attenuated the negative slope of the line. In the risk difference metric, the intersection of the (meta)regression line with the line of null effect ('cross-over' point) occurred for age at 62 years and for control-arm mortality at $44 \%$.

\section{Complications of therapy}

The complications of therapy were secondary infections, gastro-intestinal bleeding and steroid-induced hyperglycemia. No overall or low- or high-dose effects were demonstrated for any of the pooled endpoints (Table 5).

\section{Heuristics}

The considerable heterogeneity of the high-dose cohort ( $\tau=1.00,95 \% \mathrm{CrI}=0.42$ to 1.89 ) was diminished by the removal from analysis of the Schumer study [31] (Table 5 ), an effect previously noted by Minneci and colleagues [7]. This also lead to a high probability of harm in the high-dose studies $(P=89.3 \%)$ although the $\mathrm{CrI}$ for the 


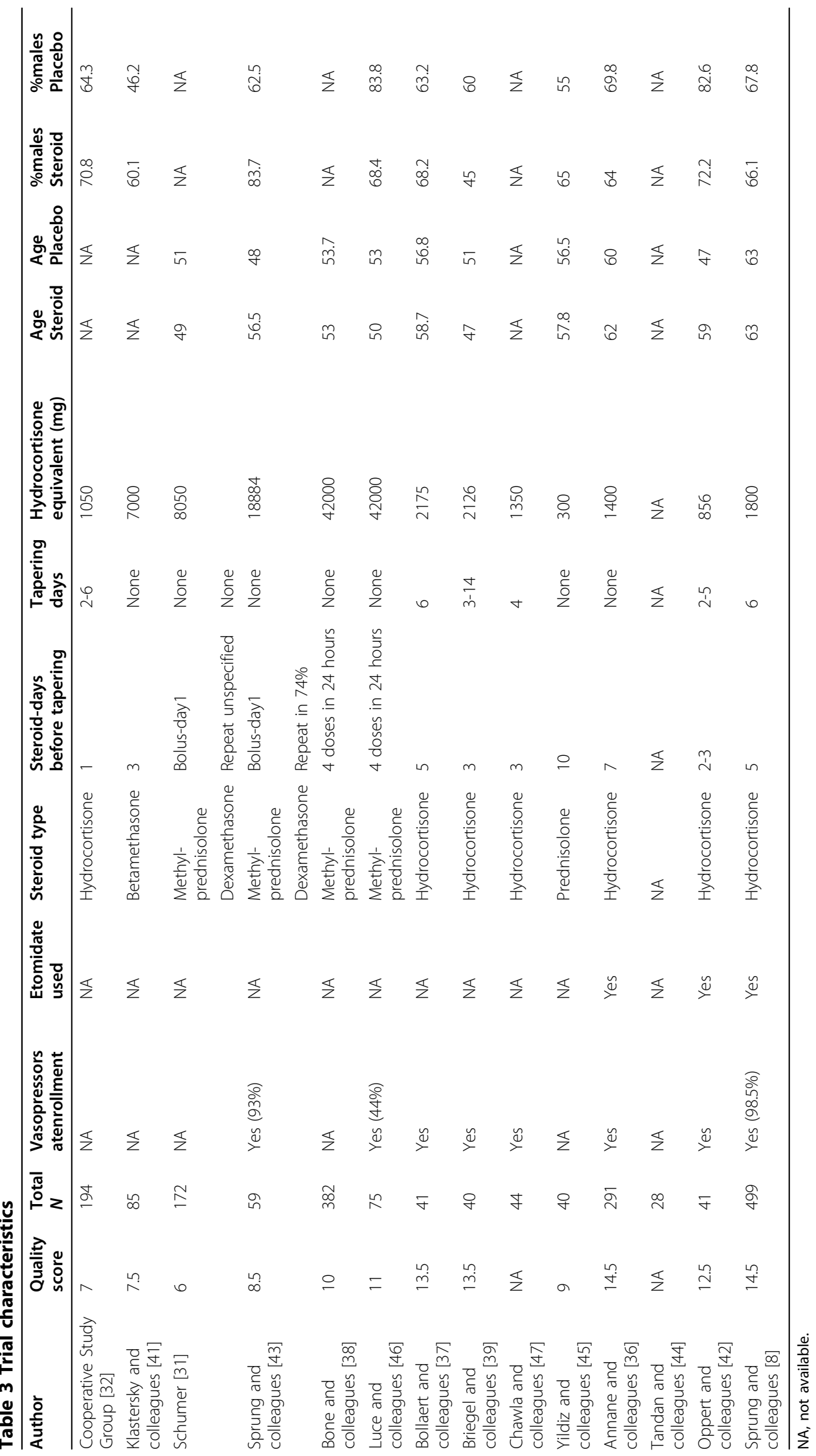




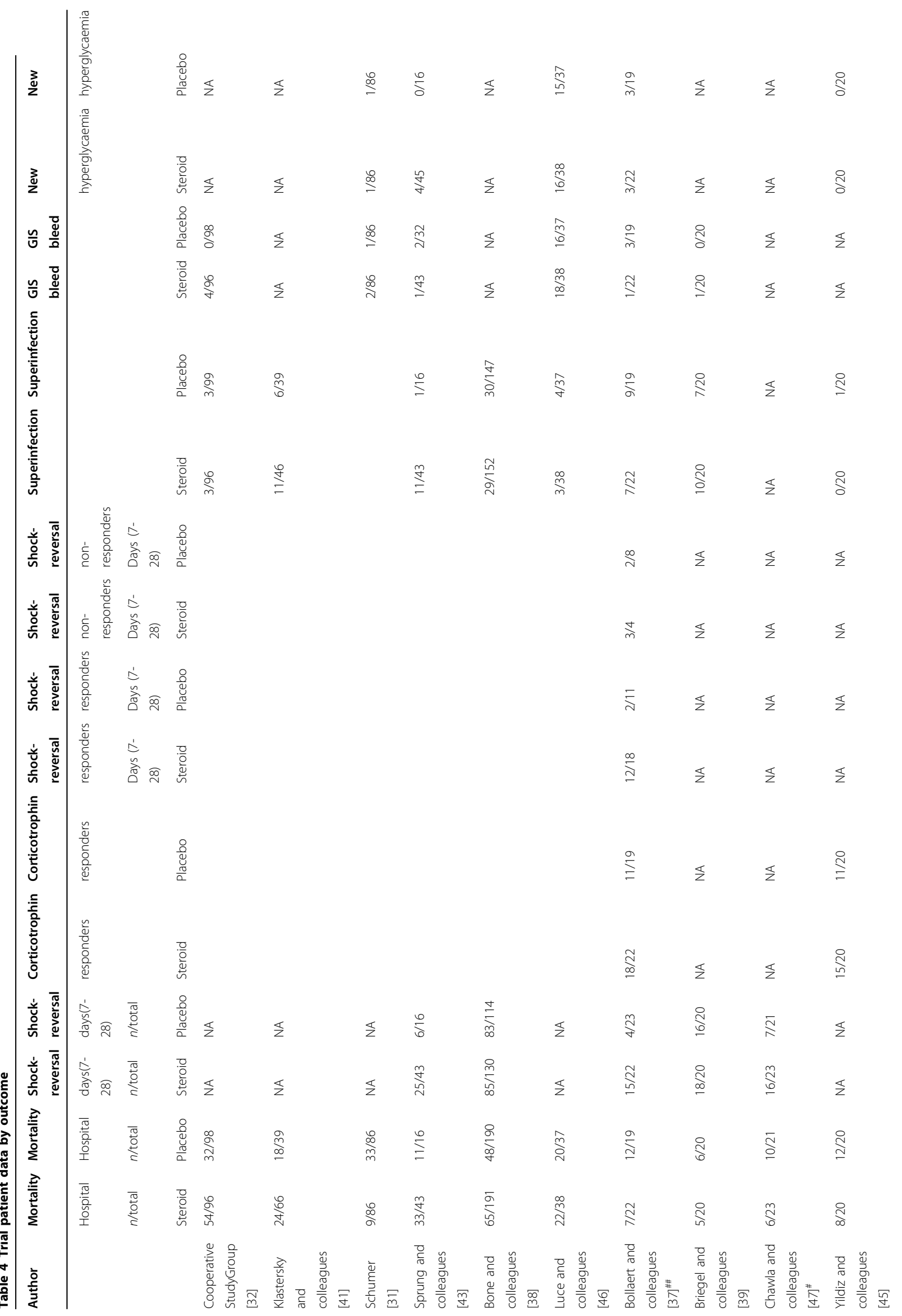


OR still included 1. Removal of the CSG study [32] from analysis resulted in reduced heterogeneity among the low-dose studies (Table 5) and a high probability of benefit in the low-dose studies $(P=5.8 \%)$ although the $\mathrm{CrI}$ for the overall OR just included 1.

In the risk difference metric the absolute risk difference (treatment versus control) for nine trials in the low-dose cohort was $-0.047(95 \% \mathrm{CrI}=-0.197$ to $0.077 ; P$ $(\mathrm{RD}>0)=21.9 \%)$; and for eight trials (CSG trial excluded [32]) was $-0.072(95 \% \mathrm{CrI}=-0.202$ to $0.018 ; P$ $(\mathrm{RD}>0)=5.3 \%)$, similar to the $6.6 \%$ reported by Annane and colleagues [48]. The mortality OR in the predictive distribution (from eight trials) was 0.703 (95\% $\mathrm{CrI}=0.156$ to $2.198 ; P(\mathrm{OR}>1)=19.9 \%)$. For hypothesized studies of size 2,000 and 4,000 patients, the mortality ORs were predicted to be $0.724(95 \% \mathrm{CrI}=0.184$ to 2.108$)$ and 0.726 ( $95 \% \mathrm{CrI}=0.184$ to 2.096$)$, respectively. The Bayesian predictive $\mathrm{P}$-value, reflecting the inconsistency of the CORTICUS study [8] with the remaining trials ( $n=7$; CSG trial excluded [32]) was 0.074 .

\section{Discussion}

Despite the disappointment of the CORTICUS [8] trial, our review suggests a modest to high probability $(80 \%$ to $98 \%$ ) of efficacy for low-dose steroids with respect to both mortality and shock reversal; the mortality effect being risk-related (Table 5). These probabilities are to be interpreted in the context of CrI spanning the null for all estimates (see Statistical analysis, above). We found no strong evidence for the determinacy of ACTH responsiveness nor complications of corticosteroid therapy. This being said, it is of interest to note the admonitory impact of the CORTICUS study on recent summary statements of sepsis management $[2,3,13,29,49]$. Consistent with previous meta-analyses $[6,7]$ we found null or adverse effects of high-dose steroids; the probability of therapeutic complications being low (Table 5).

The use of prolonged low-dose corticosteroid was justified in the landmark Annane and colleagues trial on the basis that "severe sepsis may be associated with relative adrenal insufficiency or systemic inflammationinduced glucocorticoid receptor resistance..." [36]. Apropos of this statement, it is instructive to note that the primary aim of the CORTICUS study was 28-day mortality in patients not responding to corticotrophin [8]. A recent review of corticosteroid insufficiency in the critically ill has suggested that in states where such insufficiency [50] is located "within the tissue itself... the adrenal gland function could be normal... it would be impossible to diagnose this state on the basis of serum or even tissue levels of glucocorticoids...[and]... treatment would require supraphysiological levels of 
Table 5 Outcome effect estimates

\begin{tabular}{|c|c|c|c|c|c|c|c|}
\hline \multicolumn{2}{|l|}{ Outcome } & $\mathrm{N}$ & OR $(95 \% \mathrm{Crl})$ & $P(\%)$ & $\tau(95 \% \mathrm{Crl})$ & $\beta(95 \% \mathrm{Crl})$ & $P_{\beta}(\%)$ \\
\hline \multicolumn{8}{|l|}{ Mortality } \\
\hline \multicolumn{2}{|l|}{ High dose } & 5 & $0.912(0.313$ to 1.253$)$ & 42.0 & $1.00(0.42$ to 1.89$)$ & & \\
\hline \multicolumn{2}{|c|}{ High dose excluding Schumer [31] } & 4 & 1.406 (0.727 to 2.614$)$ & 89.3 & 0.25 (0.01 to 1.40$)$ & & \\
\hline \multicolumn{2}{|c|}{ Low dose } & 9 & $0.796(0.396$ to 1.386$)$ & 20.4 & 0.65 (0.23 to 1.44$)$ & & \\
\hline \multicolumn{2}{|c|}{ Low dose excluding CSG [32] } & 8 & $0.706(0.371$ to 1.096$)$ & 5.8 & $0.39(0.04$ to 1.15$)$ & & \\
\hline \multicolumn{2}{|c|}{ Corticotrophin responders* } & 4 & 0.882 (0.285 to 2.073$)$ & 36.4 & $0.49(0.02$ to 1.78$)$ & & \\
\hline \multicolumn{2}{|c|}{ Corticotrophin non-responders* } & 4 & 0.831 (0.334 to 1.971$)$ & 28.0 & $0.43(0.02$ to 1.69$)$ & & \\
\hline \multicolumn{8}{|c|}{ Shock-reversal } \\
\hline \multicolumn{2}{|l|}{ High dose } & 2 & $1.078(0.227$ to 6.311$)$ & 54.9 & 1.39 (0.06 to 1.93$)$ & & \\
\hline \multicolumn{2}{|l|}{ Low dose } & 7 & 1.999 (1.069 to 4.55$)$ & 98.2 & 0.57 (0.04 to 1.62$)$ & & \\
\hline \multicolumn{2}{|c|}{ Corticotrophin responders* } & 3 & 1.830 (0.499 to 7.845$)$ & 86.7 & 0.87 (0.05 to -1.92$)$ & & \\
\hline \multicolumn{2}{|c|}{ Corticotrophin non-responders* } & 3 & 1.845 (0.637 to 7.267$)$ & 91.9 & 0.55 (0.02 to 1.86$)$ & & \\
\hline \multicolumn{8}{|c|}{ Meta-regression (log odds mortality) } \\
\hline \multirow[t]{3}{*}{ Average age } & High dose & 4 & 0.777 (0.285 to 2.426$)$ & 27.3 & $0.72(0.04$ to 1.87$)$ & $0.60(-0.23$ to 1.51$)$ & 94.52 \\
\hline & Excl Schumer [31] & 3 & 1.390 (0.399 to 4.872$)$ & 77.0 & $0.66(0.03$ to 1.90$)$ & $0.10(-1.57$ to 1.74$)$ & 58.05 \\
\hline & Low dose & 6 & $0.658(0.334$ to 1.223$)$ & 7.6 & $0.36(0.02$ to 1.51$)$ & 0.05 (-0.10 to 0.18$)$ & 80.53 \\
\hline \multirow[t]{4}{*}{ Underlying risk } & High dose & 5 & $0.943(0.292$ to 3.049$)$ & 45.4 & $1.14(0.46$ to 1.49$)$ & $0.23(-1.71$ to 2.58$)$ & 60.98 \\
\hline & Excl Schumer [31] & 4 & $1.372(0.596$ to 3.249$)$ & 82.9 & $0.38(0.01$ to 1.74$)$ & $-0.09(-1.31$ to 1.42$)$ & 41.47 \\
\hline & Low dose & 9 & $0.752(0.389$ to 1.291$)$ & 14.5 & $0.57(0.17$ to 1.37$)$ & $-0.49(-1.14$ to 0.27$)$ & 7.80 \\
\hline & Excl CSG [32] & 8 & $0.676(0.347$ to 1.076$)$ & 4.9 & 0.40 (0.03 to 1.23$)$ & $-0.28(-0.88$ to 0.50$)$ & 19.08 \\
\hline \multicolumn{8}{|c|}{$\begin{array}{l}\text { Odds of the following complications (corticosteroids versus } \\
\text { control) }\end{array}$} \\
\hline \multirow[t]{2}{*}{ Superinfection } & High dose & 4 & 1.127 (0.364 to 3.924$)$ & 62.2 & 0.55 (0.02 to 2.85$)$ & & \\
\hline & Low dose & 6 & 0.955 (0.388 to 1.749$)$ & 43.6 & $0.46(0.03$ to 1.62$)$ & & \\
\hline \multirow[t]{2}{*}{ Gl bleeding } & High dose & 3 & 0.824 (0.167 to 3.186$)$ & 37.3 & 0.74 (0.03 to 1.90$)$ & & \\
\hline & Low dose & 5 & 1.103 (0.379 to 3.031$)$ & 59.6 & $0.58(0.02$ to 1.84$)$ & & \\
\hline \multirow[t]{2}{*}{ Hyperglycemia } & High dose & 3 & $1.012(0.244$ to 4.266$)$ & 50.8 & 0.64 (0.03 to 1.88$)$ & & \\
\hline & Low dose & 3 & $1.430(0.155$ to 3.985$)$ & 57.4 & $0.87(0.05$ to 1.93$)$ & & \\
\hline
\end{tabular}

*all studies were low dose; $\mathrm{Cl}$, confidence interval; CSG, Cooperative Study Group; Gl, gastro-intestinal; N, number of studies reporting data for that endpoint; NA, not applicable; OR, odds ratio. Excl Sch = Excluding Schumer [31]; Excl CSG = Excluding CSG [32]

glucocorticoids" [51]. The inability in the current meta-analysis to demonstrate treatment efficacy with respect to mortality and shock-reversal based upon corticotrophin responsiveness is in agreement with Minneci and colleagues [7] and suggests both that tests of the latter to direct treatment regimens are misplaced and that the notion of adrenal insufficiency in severe sepsis and septic shock is problematic [52]; a "... hardly definable disease entity or syndrome..." [53].

Of the seven trials reporting shock-reversal $[8,36,37,39,40,42,44]$, time to the latter end-point was the primary study end-point in three $[37,39,42]$. All published studies used time-to-event analysis based upon conventional Kaplan-Meier estimates, censoring those who died and/or those in whom vasopressor therapy could not be withdrawn at time of assessment. However, such analyses are problematic, because they ignore the competing risk of those who died and/or those in whom vasopressor therapy could not be withdrawn. In the presence of competing risks Kaplan-Meier estimates cannot be interpreted as probabilities [54,55]. Under the conditions of competing risks, the probability of an event is more appropriately estimated by the cumulative incidence function, which, for the particular event of interest, is a function of the hazards of all the competing events and not solely of the hazard of the event to which it refers. Hypothesis tests for the cumulative incidence function do not necessarily equate with the familiar log-rank test [56].

How then are we to understand these favourable effects of low-dose corticosteroids? Glucocorticoid action on inflammation [57], vascular reactivity [58] and interactions between corticosteroids and 'signalling pathways' [59] may explain the salutary effects in sepsis [60]; anti-inflammatory and coagulation effects would appear to be differentially dose dependent [61]. Low or stress doses of hydrocortisone, as currently prescribed, are not replacement or physiological doses; they generate plasma cortisol levels greater than $2,500 \mathrm{nmol} / \mathrm{l}$, in excess of the usual upper limits $(1,000$ to $1,500 \mathrm{nmol} / \mathrm{l})$ of patients in septic shock $[42,60,62]$. The presumed immune-modulation [63] of these prolonged low-dose 


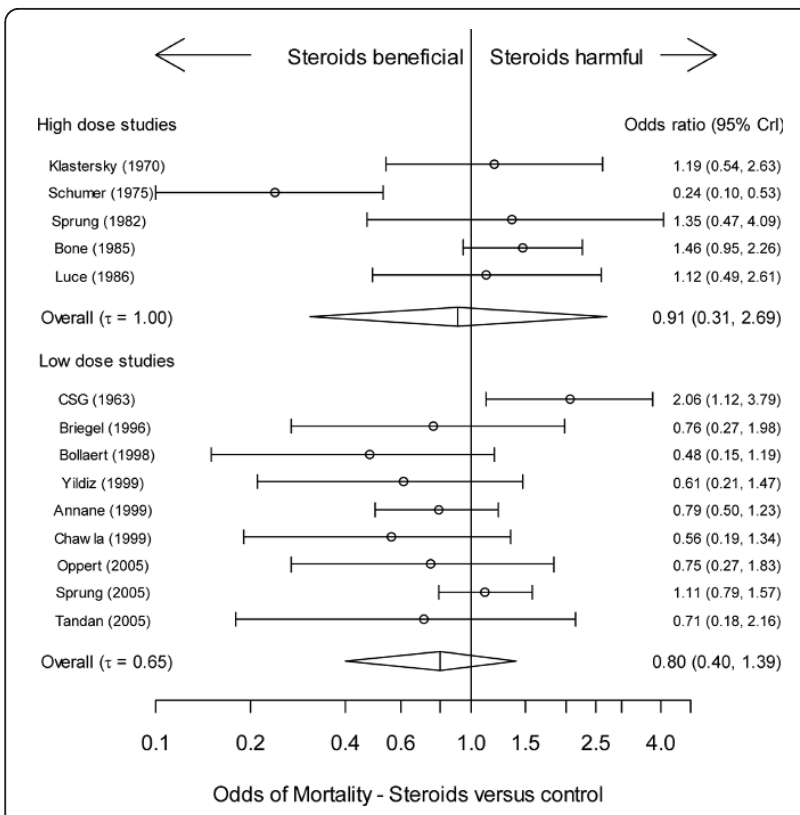

Figure 2 Corticosteroid mortality effect (OR), stratified by high (upper panel) or low (lower panel) dose steroid regimen; forest plot representation of the effect. The vertical straight line denotes null effect (odds ratio $(O R)=1$ ). The individual points denote the OR for each study and the lines on either side the 95\% Bayesian credible intervals (Crl).

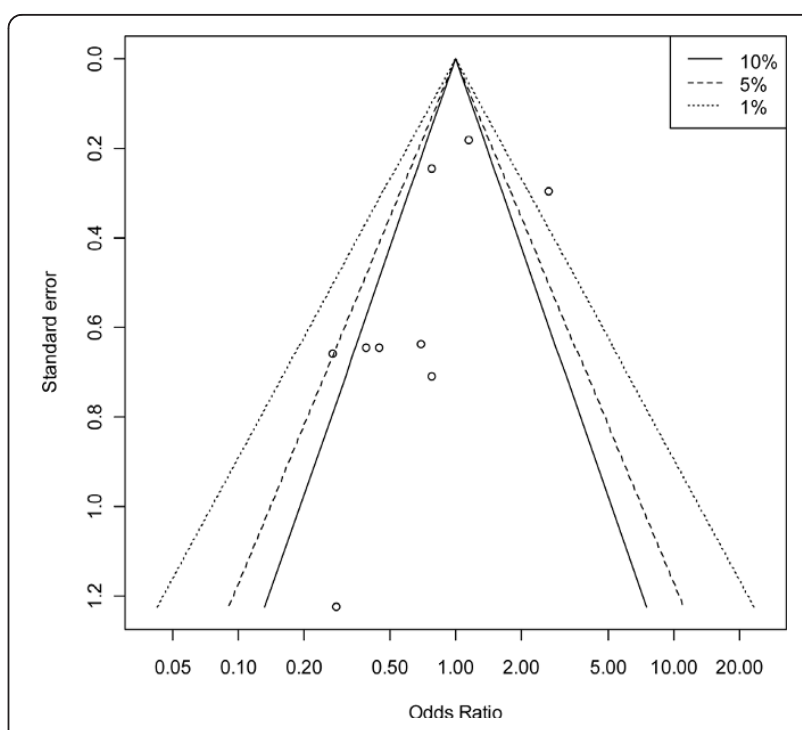

Figure 4 Contour-enhanced funnel plot of mortality odds versus standard error for low-dose corticosteroid trials $(n=9)$. Vertical axis, standard error; horizontal axis, mortality odds (log scale). The 'contours', based upon a two-sided $P$ value, are the conventional levels (not 'pseudo' confidence intervals) of statistical significance $(<0.01,<0.05,<0.1)$ for the primary studies and are independent of the pooled estimate (if the pooled estimate is biased, the contours are not affected) [33]

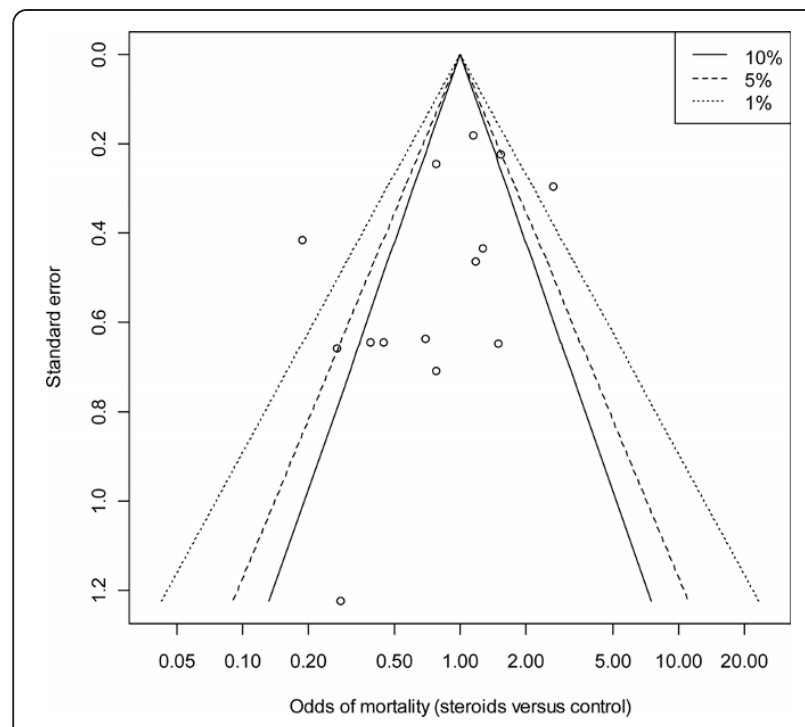

Figure 3 Contour-enhanced funnel plot of mortality odds versus standard error for all trials $(n=14)$. Vertical axis, standard error; horizontal axis, mortality odds (log scale). The 'contours', based upon a two-sided $P$ value, are the conventional levels (not 'pseudo' confidence intervals) of statistical significance $(<0.01,<0.05,<0.1)$ for the primary studies and are independent of the pooled estimate (if the pooled estimate is biased, the contours are not affected) [33].

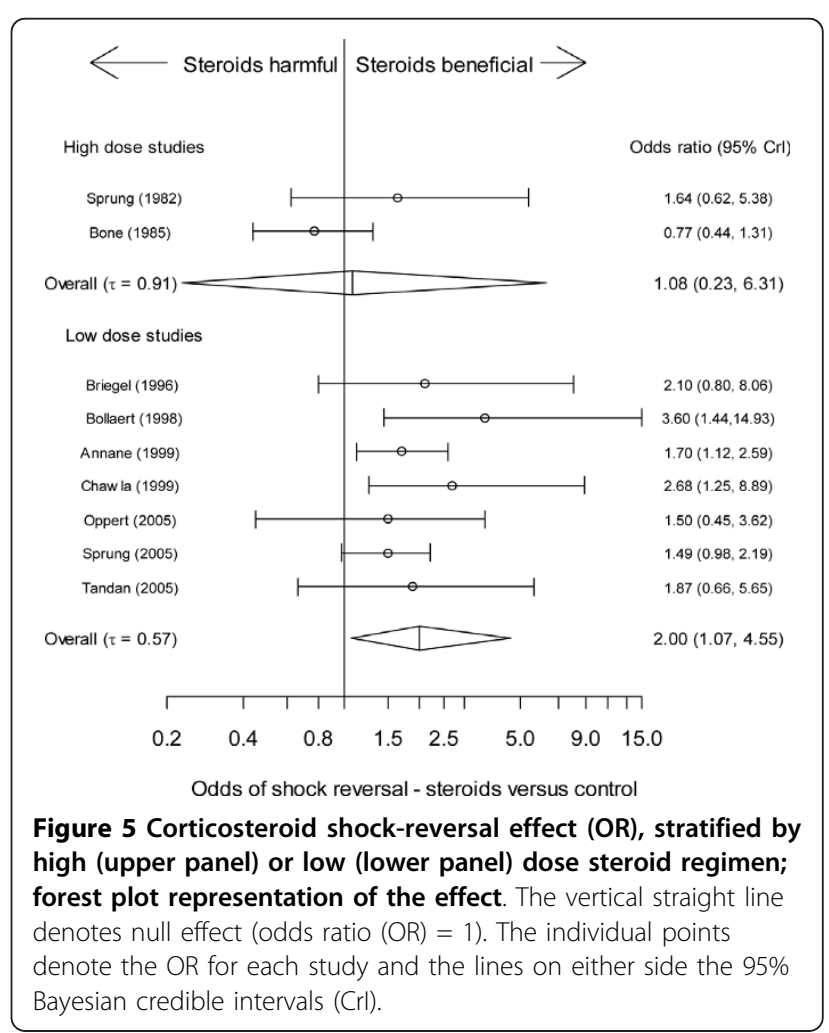


regimens underpins the rationale of critical illnessrelated corticosteroid insufficiency [14,29]. This being said, the Annane and colleagues [36] trial used a fixed seven-day steroid course without tapering and claimed efficacy and no difference in the complication rates was evident between the high-and low-dose cohorts in both the current and Annane and colleagues' meta-analyses [6]. As mentioned in commentary [64], differences in control group mortalities of the Annane and colleagues [36] and CORTICUS [8] trials may explain differing outcomes on the basis of risk-related treatment effects. The latter were persuasively demonstrated in the current meta-analysis. The estimate of mortality risk at which low-dose corticosteroids began to exhibit a treatment effect, $44 \%$, was clinically plausible given the range of control-arm mortalities of 30 to $93 \%$. Such demonstration, using appropriate Bayesian methodology [17,24], represents a novel insight into critical care therapeutic efficacy.

\section{Critique of methodology}

Our analytic approach was to consider the two treatment cohorts, high- and low-dose corticosteroid, separately; we did not produce an overall treatment effect on the basis that both the treatment intention and effective (daily) corticosteroid dose of the two cohorts were quite disparate. An alternate approach would have been to consider all trials $(n=14)$ with total hydrocortisone dose or calendar year as effect-moderators. In the absence of individual patient data, such analyses, with only 14 studies, have low power.

Secondary outcome analysis was beset by selection bias in reporting [65], as witnessed by study numbers in Table 5; parameter estimates may be biased under such circumstances. The study list addressing low-dose corticosteroid mortality efficacy $(n=9)$ included a single study [32] in 1963, the others being from the period 1996 to 2005 (Figure 2). Plausible estimates of current therapeutic efficacy would suggest analysis excluding the former study, the result of which was to reduce heterogeneity of the mortality effect by $40 \%$ and to reveal a probability of corticosteroid efficacy of $94.2 \%$ (Table 5). The single-investigator single-centre Schumer study, conducted over a prolonged eight-year period, has been previously subject to substantive critique [7] and recent cautions regarding extended recruitment time [66] and inference from single-center studies [67] merits its consideration as an outlier.

That the inclusion of the large but null-effect CORTICUS trial [8] in the current meta-analysis did not extinguish a probable treatment effect deserves comment. The impact of the single large trial is undoubted, but the evidence produced by such a trial may be "less reliable than its statistical analysis suggests" [68]. We adopted a random effects methodology [69] in the presence of moderate between study heterogeneity $(\tau$, Table 5 ); under these conditions large studies may have little impact upon a meta-analysis [70] and there may be virtue in (clinical) heterogeneity [71]. The degree of asymmetry of the contour-enhanced funnel plot in the low-dose cohort (see Results, Mortality outcome, above) raises concerns about a random effects methodology [69], but there was no quantitative evidence of smallstudy effects (at the 0.1 level) and the number of studies was small. In the presence of sparse data and moderate heterogeneity (Table 5), the interpretation of funnel plot asymmetry is problematic $[34,72]$ and exploration of the reasons for such heterogeneity is the preferred analytic focus [34].

With respect to the efficacy of corticosteroids in severe sepsis and septic shock, the divergent positions represented by the Annane and colleagues [36] and CORTICUS [8] trials remain unresolved. Two recent (calendar year 2009) updates $[48,73]$ of previous metaanalyses [6,7] also merit comment. Both of the updated meta-analyses, using frequentist methodology, found efficacy of low-dose prolonged corticosteroids with respect to the mortality effect, Annane and colleagues [48] found a relative risk of 0.84 ( $95 \%$ confidence interval $(\mathrm{CI})=0.72$ to $0.97 ; P=0.02)$ and Minneci and colleagues [73] found an OR of 0.64 (95\% CI $=0.45$ to $0.93 ; P=0.02$ ), and shock reversal, the latter effect consistent with the estimates of the current study (Table 5). Study inclusions in these meta-analyses differed and were not the same as in our meta-analysis, which adopted a rigorous exclusion policy (Table 1). The frequentist meta-regression methods used by both metaanalyses $[48,73]$ to estimate the risk-related treatment efficacy of steroids are problematic [17,24]. Although such methods may identify putative risk related treatment effects in meta-analyses they fail to allow for both regression to the mean (the difference between outcome and baseline being correlated with baseline) and the stochastic nature of the control rate (regression dilution bias). The stochastic characteristic of the control rate is also not addressed as the expected response in (ordinary) linear regression is conditional upon independent (fixed) variables and there is no inherent accounting for the random error in estimation of this control rate. Such problems are overcome by the use of Bayesian methods $[17,24]$.

Both meta-analyses were judicious in their conclusions about treatment efficacy and this was reiterated by an accompanying editorial [74]. However, neither study was able to attend to this uncertainty in a tangible manner. This is precisely what our Bayesian analysis quantifies: what was the probability of treatment efficacy. For example, our analysis demonstrated that the probability 
of adverse mortality outcome with low-dose corticosteroids (outlier excluded) was 5.8\% (Table 5). The omission of such a probability statement cannot be justified by an appeal to "the nominal $P$ values for these outcomes were very close to $0.05 . . . . "$ [48]. We have previously cautioned the against interpretation of 95\% CI (and associated frequentist $P$ values) as probability statements [75]. Furthermore, neither meta-analysis reported exploration of estimates from a predictive distribution, which may be considered as a more appropriate future treatment summary than the mean effect [18]. Such a capacity recommends Bayesian methodology, although meta-analytic prediction intervals, which address the "... dispersion of the effect sizes..." are computable from a frequentist perspective [76]. With respect to reservations expressed regarding the status of the CORTICUS study $[29,74]$, we found no compelling evidence (Bayesian predictive $P$-value 0.074$)$ that this trial was inconsistent with the remaining $(n=7)$ trials.

Continued controversy and conventional wisdom [77] would appear to mandate the conduct of a large(mega)-trial of this therapy in well-defined patient subsets; an absolute treatment effect of $7.2 \%$, control arm risk of $54 \%$ and $90 \%$ power would suggest a total patient number of greater than 2,000. This being said our predictive estimates were unable to suggest efficacy for future 'large' trials, albeit the trial base from which these estimates were made was small.

\section{Conclusions}

Although a null effect for mortality treatment efficacy of low-dose corticosteroid therapy in severe sepsis and septic shock could not be excluded, there appears to be credible evidence for shock reversal efficacy. Similarly, although a null effect was not excluded, advantageous effects of low-dose steroids had a high probability of dependence upon patient age and underlying risk. Lowdose steroid efficacy was not demonstrated in corticotrophin non-responders. Bayesian methods are apposite to express uncertainty in efficacy estimates from metaanalyses.

\section{Key messages}

- The efficacy of corticosteroids in patients with severe sepsis and septic shock is uncertain despite recent meta-analytic reviews.

- Bayesian methods are apposite to express uncertainty in efficacy estimates from meta-analyses.

- The efficacy of low-dose corticosteroids had a high probability of dependence upon patient age and underlying risk; low-dose steroid efficacy was not demonstrated in corticotrophin non-responders.

- Bayesian meta-analytic predictive estimates were unable to suggest efficacy for future large trials.
- A null effect for mortality treatment efficacy of low-dose corticosteroid therapy in severe sepsis and septic shock could not be excluded.

\section{Additional material}

\section{Additional file 1: Electronic search strategy. Detailed search strategy} of electronic databases

\section{Abbreviations}

ACCP: American College of Chest Physicians; ACTH: adreno-corticotrophin hormone; Cl: confidence interval; CORTICUS: Corticosteroid Therapy of Septic Shock; Crl: credible intervals; CSG: Cooperative Study Group; OR: odds ratio; SCCM: Society of Critical Care Medicine.

\section{Author details}

'Department of Intensive Care Medicine, The Queen Elizabeth Hospital, 28 Woodville Road, Woodville, South Australia 5011, Australia. ${ }^{2}$ Department of Statistics, Faculty of Science, Macquarie University, Balaclava Road, North Ryde, NSW 2109, Australia. ${ }^{3}$ Department of Library Services, The Queen Elizabeth Hospital, 28 Woodville Road, Woodville, South Australia 5011, Australia. ${ }^{4}$ Department of Critical Care Medicine, Flinders Medical Centre and School of Medicine, Flinders University, Sturt Road, Bedford Park, South Australia 5042, Australia.

\section{Authors' contributions}

The study was conceived by JLM, PLG and AB. SR constructed the search terms and conducted the electronic search. JLM, PLG and $A B$ reviewed studies fulfilling inclusion criteria and pre-defined variables. JLM, and PLG conducted the quality assessment and statistical analysis. All authors contributed to the writing of the paper, critical review and final approval.

\section{Competing interests}

The authors declare that they have no competing interests.

Received: 16 September 2009 Revised: 25 May 2010

Accepted: 13 July 2010 Published: 13 July 2010

\section{References}

1. Weitzman S, Berger S: Clinical trial design in studies of corticosteroids for bacterial infections. Ann Intern Med 1974, 81:36-42.

2. Keh $D$, Weber-Carstens $S$, Ahlers $O$ : Adjunctive therapies in severe sepsis and septic shock: Current place of steroids. Current Infectious Disease Reports 2008, 10:354-361.

3. Mesotten D, Vanhorebeek I, Van den Berghe G: The altered adrenal axis and treatment with glucocorticoids during critical illness. Nat Clin Pract Endocrinol Metab 2008, 4:496-505.

4. Cronin L, Cook DJ, Carlet J, Heyland DK, King D, Lansang MA, Fisher CJ Jr: Corticosteroid treatment for sepsis: A critical appraisal and meta-analysis of the literature. Crit Care Med 1995, 23:1430-1439.

5. Lefering RM, Neugebauer EAMP: Steroid controversy in sepsis and septic shock: A meta-analysis. Crit Care Med 1995, 23:1294-1303.

6. Annane D, Bellissant E, Bollaert PE, Briegel J, Keh D, Kupfer Y: Corticosteroids for severe sepsis and septic shock: a systematic review and meta-analysis. BMJ 2004, 329:480.

7. Minneci PCM, Deans KJM, Banks SMP, Eichacker PQM, Natanson CM: Metaanalysis: the effect of steroids on survival and shock during sepsis depends on the dose. Ann Intern Med 2004, 141:47-56.

8. Sprung $C L$, Annane D, Keh D, Moreno R, Singer M, Freivogel $K$, Weiss $Y G$, Benbenishty J, Kalenka A, Forst H, Laterre PF, Reinhart K, Cuthbertson BH, Payen D, Briegel J, CORTICUS Study Group: Hydrocortisone therapy for patients with septic shock. N Engl J Med 2008, 358:111-124.

9. Annane D, Briegel J, Keh D, Moreno R, Singer M, Sprung CL, Corticus Study Coordinators: Clinical equipoise remains for issues of adrenocorticotropic hormone administration, cortisol testing, and therapeutic use of hydrocortisone. Crit Care Med 2003, 31:2250-2251. 
10. Minneci PC, Deans KJ, Banks SM, Eichacker PQ, Natanson C: Corticosteroids for Septic Shock. Ann Intern Med 2004, 141:742-743.

11. Annane D: Cortisol replacement for severe sepsis and septic shock: what should I do? Critical Care 2002, 6:190-191.

12. Vincent JL: Steroids in sepsis: another swing of the pendulum in our clinical trials. Critical Care 2008, 12:141.

13. Dellinger RP, Levy MM, Carlet JM, Bion J, Parker MM, Jaeschke R, Reinhart K, Angus DC, Brun-Buisson C, Beale R, Calandra T, Dhainaut JF, Gerlach H, Harvey M, Marini JJ, Marshall J, Ranieri M, Ramsay G, Sevransky J, Thompson BT, Townsend S, Vender JS, Zimmerman JL, Vincent JL, International Surviving Sepsis Campaign Guidelines Committee; American Association of Critical-Care Nurses; American College of Chest Physicians; American College of Emergency Physicians; Canadian Critical Care Society; European Society of Clinical Microbiology and Infectious Diseases; European Society of Intensive Care Medicine; European Respiratory Society; International Sepsis Forum; Japanese Association for Acute Medicine; Japanese Society of Intensive Care Medicine; Society of Critical Care Medicine; Society of Hospital Medicine; Surgical Infection Society; World Federation of Societies of Intensive and Critical Care Medicine: Surviving Sepsis Campaign: international guidelines for management of severe sepsis and septic shock: 2008. Crit Care Med 2008, 36:296-327.

14. Marik PE, Pastores SM, Annane D, Meduri GU, Sprung CL, Arlt W, Keh D, Briegel J, Beishuizen A, Dimopoulou I, Tsagarakis S, Singer M, Chrousos GP, Zaloga G, Bokhari F, Vogeser M, American College of Critical Care Medicine: Recommendations for the diagnosis and management of corticosteroid insufficiency in critically ill adult patients: Consensus statements from an international task force by the American College of Critical Care Medicine. Crit Care Med 2008, 36:1937-1949.

15. Shojania KG, Sampson M, Ansari MT, Ji J, Doucette S, Moher D: How quickly do systematic reviews go out of date? A survival analysis. Ann Intern Med 2007, 147:224-233.

16. Finfer S: Corticosteroids in septic shock. N Engl J Med 2008, 358:188-190.

17. Sharp SJ, Thompson SG: Analysing the relationship between treatment effect and underlying risk in meta-analysis: comparison and development of approaches. Stat Med 2000, 19:3251-3274.

18. Spiegelhalter DJ, Abrams KR, Myles JP: Bayesian approaches to clinical trials and health-care evaluation Chichester: John Wiley \& Sons, Ltd 2004.

19. Bone RC, Balk RA, Cerra FB, Dellinger RP, Fein AM, Knaus WA, Schein RM, Sibbald WJ: Definitions for sepsis and organ failure and guidelines for the use of innovative therapies in sepsis. The ACCP/SCCM Consensus Conference Committee. American College of Chest Physicians/Society of Critical Care Medicine. Chest 1992, 101:1644-1655.

20. Peter JV, John P, Graham PL, Moran JL, George IA, Bersten A: Corticosteroids in the prevention and treatment of acute respiratory distress syndrome (ARDS) in adults: meta-analysis. BMJ 2008, 336:1006-1009.

21. Warn DE, Thompson SG, Spiegelhalter DJ: Bayesian random effects metaanalysis of trials with binary outcomes: methods for the absolute risk difference and relative risk scales. Stat Med 2002, 21:1601-1623.

22. Lunn DJ, Thomas A, Best N, Spiegelhalter D: WinBUGS - A Bayesian modelling framework: Concepts, structure, and extensibility. Statistics and Computing 2000, 10:325-337.

23. Spruance SL, Reid JE, Grace M, Samore M: Hazard ratio in clinical trials. Antimicrob Agents Chemother 2004, 48:2787-2792.

24. Moran J, Solomon P, Warn D: Methodology in meta-analysis: a study from Critical Care meta-analytic practice. Health Services and Outcomes Research Methodology 2004, 5:207-226.

25. Sutton AJ, Cooper NJ, Abrams KR, Lambert PC, Jones DR: A Bayesian approach to evaluating net clinical benefit allowed for parameter uncertainty. J Clin Epidemiol 2005, 58:26-40.

26. Wijeysundera DN, Austin PC, Hux JE, Beattie WS, Laupacis A: Bayesian statistical inference enhances the interpretation of contemporary randomized controlled trials. J Clin Epidemiol 2009, 62:13-21.

27. Woolcott JC, Richardson K, Wiens MO, Patel B, Marin J, Khan KM, Marra CA: Meta-analysis of the impact of 9 medication classes on falls in elderly persons. Arch Intern Med 2009, 169:1952-1960.

28. Aitkin $M$, Francis B, Hinde J, Darnell R: Statistical modelling and inference. Statistical Modelling in R Oxford OX2 6DP, UK: Oxford University Press 2009, 28-96.

29. Marik PE: Critical illness-related corticosteroid insufficiency. Chest 2009, 135:181-193.
30. Rucker G, Schwarzer G, Carpenter J, Schumacher M: Undue reliance on $1 \wedge 2$ in assessing heterogeneity may mislead. BMC Med Res Methodol 2009, 8.

31. Schumer W: Steroids in the treatment of clinical septic shock. Ann Surg 1976, 184:333-341.

32. Cooperative Study Group: The effectiveness of hydrocortisone in the management of severe infections. JAMA 1963, 183:462-465.

33. Peters $J \mathrm{~L}$, Sutton AJ, Jones DR, Abrams KR, Rushton L: Contour-enhanced meta-analysis funnel plots help distinguish publication bias from other causes of asymmetry. J Clin Epidemiol 2008, 61:991-996.

34. Harbord RM, Egger M, Sterne JA: A modified test for small-study effects in meta-analyses of controlled trials with binary endpoints. Stat Med 2006, 25:3443-3457.

35. Schwarzer G: meta: Meta-analysis.[http://cran.r-project.org/web/packages/ meta/index.html].

36. Annane D, Sebille V, Charpentier C, Bollaert PE, Francois B, Korach JM, Capellier G, Cohen Y, Azoulay E, Troché G, Chaumet-Riffaud P, Bellissant E: Effect of treatment with low doses of hydrocortisone and fludrocortisone on mortality in patients with septic shock. JAMA 2002, 288:862-871.

37. Bollaert PE, Charpentier C, Levy B, Debouverie M, Audibert G, Larcan A: Reversal of late septic shock with supraphysiologic doses of hydrocortisone. Crit Care Med 1998, 26:645-650.

38. Bone RC, Fisher CJ Jr, Clemmer TP, Slotman GJ, Metz CA, Balk RA: A controlled clinical trial of high-dose methylprednisolone in the treatment of severe sepsis and septic shock. N Engl J Med 1987, 317:653-658.

39. Briegel J, Forst $\mathrm{H}$, Haller M, Schelling G, Kilger E, Kuprat G, Hemmer B, Hummel T, Lenhart A, Heyduck M, Stoll C, Peter K: Stress doses of hydrocortisone reverse hyperdynamic septic shock: a prospective, randomized, double-blind, single-center study. Crit Care Med 1999, 27:723-732.

40. Chawla K, Kupfer Y, Tessler S: Prognostic value of cortisol response in septic shock. JAMA 2000, 284:309.

41. Klastersky J, Cappel R, Debusscher L: Effectiveness of betamethasone in management of severe infections. A double-blind study. N Engl J Med 1971, 284:1248-1250.

42. Oppert M, Schindler R, Husung C, Offermann K, Graf K, Boenisch O, Barckow D, Frei U, Eckardt KU: Low-dose hydrocortisone improves shock reversal and reduces cytokine levels in early hyperdynamic septic shock. Crit Care Med 2005, 33:2457-2464.

43. Sprung CL, Caralis PV, Marcial EH, Pierce M, Gelbard MA, Long WM, Duncan RC, Tendler MD, Karpf M: The effects of high-dose corticosteroids in patients with septic shock. A prospective, controlled study. $N$ Engl J Med 1984, 311:1137-1143.

44. Tandan SM, Guleria R, Gupta N: Low dose steroids and adrenocortical insufficiency in septic shock: A double-blind randomised controlled trial from India. Am J Respir Crit Care Med 2005, 171:A43.

45. Yildiz O, Doganay M, Aygen B, Guven M, Kelestimur F, Tutuu A: Physiological-dose steroid therapy in sepsis. Critical Care (London, England) 2002, 6:251-259.

46. Luce JM, Montgomery AB, Marks JD, Turner J, Metz CA, Murray JF: Ineffectiveness of high-dose methylprednisolone in preventing parenchymal lung injury and improving mortality in patients with septic shock. Am Rev Respir Dis 1988, 138:62-68.

47. Chawla K, Kupfer Y, Goldman I, Tessler S: Hydrocortisone reverses refractory septic shock. Crit Care Med 1999, 27:33A.

48. Annane D, Bellissant E, Bollaert PE, Briegel J, Confalonieri M, De Gaudio R, Keh D, Kupfer Y, Oppert M, Meduri GU: Corticosteroids in the treatment of severe sepsis and septic shock in adults: a systematic review. JAMA 2009, 301:2362-2375

49. Sprung $\mathrm{CL}$, Annane D: Corticosteroids in septic shock. Controversies in Intensive Care Medicine Berlin: Medizinisch Wissenschaftliche VerlagsgesellschaftKuhlen R, Moreno R, Ranieri M, Rhodes A 2008, 205-210.

50. Schaaf MJM, Cidlowski JA: Molecular mechanisms of glucocorticoid action and resistance. J Steroid Biochem Mol Biol 2002, 83:37-48.

51. Cooper MS, Stewart PM: Adrenal Insufficiency in Critical IIIness. I Intensive Care Med 2007, 22:348-362.

52. Dickstein G: On the term "relative adrenal insufficiency"-or what do we really measure with adrenal stimulation tests? I Clin Endocrinol Metab 2005, 90:4973-4974. 
53. de Jong MFC, Beishuizen A, Groeneveld AB: Defining relative adrenal insufficiency in the critically ill: The ACTH test revisited. Yearbook of Intensive Care and Emergency Medicine Berlin: Springer-VerlagVincent J 2006, 539-551.

54. Pintilie M: Competing risks: A practical perspective Chichester, UK: John Wiley \& Sons Ltd 2006

55. Southern DA, Faris PD, Brant R, Galbraith PD, Norris CM, Knudtson ML, Ghali WA, APPROACH Investigators: Kaplan-Meier methods yielded misleading results in competing risk scenarios. J Clin Epidemiol 2006, 59:1110-1114.

56. Williamson PR, Kolamunnage-Dona $\mathrm{R}$, Smith $\mathrm{CT}$ : The influence of competing risks setting on the choice of hypothesis test for treatment effect. Biostat 2007, 8:689-694.

57. Rhen T, Cidlowski JA: Antiinflammatory action of glucocorticoids - new mechanisms for old drugs. N Engl J Med 2005, 353:1711-1723.

58. Yang S, Zhang L: Glucocorticoids and vascular reactivity. Current Vascular Pharmacology 2004, 2:1-12.

59. Russell JA, Walley KR, Gordon AC, Cooper DJ, Hébert PC, Singer J, Holmes CL, Mehta S, Granton JT, Storms MM, Cook DJ, Presneill JJ, Dieter Ayers for the Vasopressin and Septic Shock Trial Investigators: Interaction of vasopressin infusion, corticosteroid treatment, and mortality of septic shock. Crit Care Med 2009, 37:811-818.

60. Keh D, Boehnke T, Weber-Cartens S, Schulz C, Ahlers O, Bercker S, et al: Immunologic and hemodynamic effects of "low-dose" hydrocortisone in septic shock: a double-blind, randomized, placebo-controlled, crossover study. Am J Respir Crit Care Med 2003, 167:512-520.

61. de Kruif MD, Lemaire LC, Giebelen IA, van Zoelen MA, Pater JM, van den Pangaart PS, Groot AP, de Vos AF, Elliott PJ, Meijers JC, Levi M, van der Poll T: Prednisolone dose-dependently influences inflammation and coagulation during human endotoxemia. J Immunol 2007, 178:1845-1851.

62. Arafah BM: Hypothalamic pituitary adrenal function during critical illness: limitations of current assessment methods. J Clin Endocrinol Metab 2006, 91:3725-3745.

63. Minneci P, Deans K, Natanson C, Eichacker PQ: Increasing the efficacy of anti-inflammatory agents used in the treatment of sepsis. European Journal of Clinical Microbiology \& Infectious Diseases 2003, 22:1-9.

64. Seam N: Corticosteroids for septic shock: correspondence. N Engl J Med 2008, 358:2068-2069.

65. Williamson PR, Gamble C, Altman DG, Hutton JL: Outcome selection bias in meta-analysis. Stat Methods Med Res 2005, 14:515-524.

66. Annane D: Improving clinical trials in the critically ill: unique challengesepsis. Crit Care Med 2009, 37:S117-S128.

67. Bellomo RMFF, Warrillow SJM, Reade MCM: Why we should be wary of single-center trials. Crit Care Med 2009, 37:3114-3119.

68. Borm GF, Lemmers O, Fransen J, Donders R: The evidence provided by a single trial is less reliable than its statistical analysis suggests. J Clin Epidemiol 2009, 62(62(7)):711-715, e1.

69. Higgins JPT, Thornton A, Spiegelhalter DJ: A re-evaluation of randomeffects meta-analysis. J R Stat Soc Ser A Stat Soc 2009, 172:137-159.

70. Sutton AJ, Cooper NJ, Jones DR, Lambert PC, Thompson JR, Abrams KR: Evidence-based sample size calculations based upon updated metaanalysis. Stat Med 2007, 26:2479-2500.

71. Shrier I, Platt RW, Steele RJ: Mega-trials vs. meta-analysis: Precision vs. heterogeneity? Contemporary Clinical Trials 2007, 28:324-328.

72. Terrin N, Schmid CH, Lau J: In an empirical evaluation of the funnel plot, researchers could not visually identify publication bias. J Clin Epidemiol 2005, 58:894-901.

73. Minneci PC, Deans KJ, Eichacker PQ, Natanson C: The effects of steroids during sepsis depend on dose and severity of illness: an updated metaanalysis. Clinical Microbiology and Infection 2009, 15:308-318.

74. Jaeschke $R$, Angus DC: Living with uncertainty in the intensive care unit: should patients with sepsis be treated with steroids? JAMA 2009, 301:2388-2390.

75. Moran $J$, Bersten AD, Solomon PJ: Meta-analysis of controlled trials of ventilator therapy in acute lung injury and acute respiratory distress syndrome: an alternative perspective. Intensive Care Med 2005, 31:227-235.

76. Borenstein M, Hedges LV, Higgins JP, Rothstein HR: Introduction to Metaanalysis West Sussex, UK: John Wiley \& Sons, Ltd 2009.

77. Finfer S: Corticosteroids in septic shock. N Engl J Med 2008, 358:188-190.
78. Wagner HN, Bennett IL, Lasagna L, Cluff LE, Rosenthal MB, Mirick GS: The effect of hydrocortisone upon the course of pneumococcal pneumonia treated with penicillin. Bull Johns Hopkins Hosp 1955, 98:197-215.

79. Thompson WL, Gurley HT, Lutz BA, Jackson BL, Kyols LK, Morris IA: Inefficacy of glucocorticoids in shock (double-blinded study). Clin Res 1976, 24:258A.

80. Lucas CE, Ledgerwood AM: The cardiopulmonary response to massive doses of steroids in patients with septic shock. Arch Surg 1984, 119:537-541.

81. The Veterans Administration Systemic Sepsis Cooperative Study Group: Effect of high-dose glucocorticoid therapy on mortality in patients with clinical signs of systemic sepsis. The Veterans Administration Systemic Sepsis Cooperative Study Group. N Engl J Med 1987, 317:659-665.

82. Schattner A, el-Hador I, Hahn T, Landau Z: Triple anti-TNF-alpha therapy in early sepsis: a preliminary report. J Int Med Res 1997, 25:112-116.

83. Confalonieri M, Urbino R, Potena A, Piattella M, Parigi P, Puccio G, Della Porta R, Giorgio C, Blasi F, Umberger R, Meduri GU: Hydrocortisone infusion for severe community-acquired pneumonia: a preliminary randomized study. Am J Respir Crit Care Med 2005, 171:242-248.

84. Rinaldi S, Adembri C, Grechi S, De Gaudio AR: Low-dose hydrocortisone during severe sepsis: effects on microalbuminuria. Crit Care Med 2006, 34:2334-2339.

85. Huh JW, Lim CM, Koh Y, Hong SB: Effect of low doses of hydrocortisone in patient with septic shock and relative adrenal insufficiency: 3 days versus 7 days treatment. Crit Care Med 2006, 34:A101.

86. Loisa P, Parviainen I, Tenhunen J, Hovilehto S, Ruokonen E: Effect of mode of hydrocortisone administration on glycemic control in patients with septic shock: a prospective randomized trial. Crit Care 2007, 11:R21.

87. Nawab Q, Golden E, Confalonieri M, Umberger R, Meduri GU: Glucocorticoid (GC) Treatment in Severe Community-Acquired Pneumonia (CAP): Comparison of Hydrocortisone [HC] vs. Methylprednisolone [MP]. American Thoracic Society: International Conference 2007, A594.

88. Cicarelli DD, Vieira JE, Bensenor FE: Early dexamethasone treatment for septic shock patients: A prospective randomized clinical trial. Sao Paulo Medical Journal 2007, 125:237-241.

89. Kurugundla N, Irugulapati L, Kilari D, Amchentsev A, Devakonda A, George L, Raoof S: Effect of steroids in septic shock patients without relative adrenal insufficiency. American Thoracic Society: International Conference 2008, A116.

doi:10.1186/cc9182

Cite this article as: Moran et al:: Updating the evidence for the role of corticosteroids in severe sepsis and septic shock: a Bayesian metaanalytic perspective. Critical Care 2010 14:R134.

\section{Submit your next manuscript to BioMed Central and take full advantage of:}

- Convenient online submission

- Thorough peer review

- No space constraints or color figure charges

- Immediate publication on acceptance

- Inclusion in PubMed, CAS, Scopus and Google Scholar

- Research which is freely available for redistribution

Submit your manuscript at www.biomedcentral.com/submit
C Biomed Central 